This item was submitted to Loughborough's Research Repository by the author.

Items in Figshare are protected by copyright, with all rights reserved, unless otherwise indicated.

\title{
Assessing perceived need support and need satisfaction in physical education: adaptation and validation with English students
}

PLEASE CITE THE PUBLISHED VERSION

https://doi.org/10.1080/1091367X.2018.1461627

\section{PUBLISHER}

(C) Taylor \& Francis (Routledge)

\section{VERSION}

AM (Accepted Manuscript)

\section{PUBLISHER STATEMENT}

This is an Accepted Manuscript of an article published by Taylor \& Francis in Measurement in Physical Education and Exercise Science on 25 Apr 2018, available online:

https://doi.org/10.1080/1091367X.2018.1461627

\section{LICENCE}

CC BY-NC-ND 4.0

\section{REPOSITORY RECORD}

Oliva, D. Sanchez, Florence Kinnafick, Nathan Smith, and A. Stenling. 2019. "Assessing Perceived Need Support and Need Satisfaction in Physical Education: Adaptation and Validation with English Students". figshare. https://hdl.handle.net/2134/32668. 


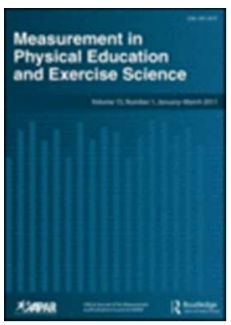

\section{Assessing perceived need support and need satisfaction in school physical education: Initial validity evidence with English-speaking adolescents}

\begin{tabular}{|r|l|}
\hline Journal: & Measurement in Physical Education and Exercise Science \\
\hline Manuscript ID & HMPE-2017-0010.R3 \\
\hline Manuscript Type: & Original Article \\
\hline Keywords: & $\begin{array}{l}\text { Validation, psychological need support, psychological need satisfaction, } \\
\text { self-determination theory, physical education }\end{array}$ \\
\hline \multicolumn{2}{|l}{} \\
\hline
\end{tabular}

SCHOLARONE ${ }^{\text {M }}$

Manuscripts 
1

2 This study aimed to validate an English version of two questionnaires to analyze perceived

3 psychological need support and need satisfaction in the physical education context. Participants

$4 \quad$ included 453 students aged between 12 and 17 years. For the psychological need-support scale

5 (BPNSQ) the hypothesized 3-factor solution displayed high interfactor correlations ( $\mathrm{rs}>1$ ), and a

6 follow-up analysis indicated that the items were represented by a single need-support factor. For the

7 psychological need-satisfaction scale (BPN-PE), we found support for the hypothesized 3-factor

8 solution. Both scales were found invariant across gender, and the nomological validity was also

9 demonstrated through the associations between factors of both scales. This study provides initial

10 support for the use of the Basic Psychological Needs Support Questionnaire (BPNSQ) and the Basic

11 Psychological Needs in Physical Education Scale (BPN-PE) to assess perceptions of psychological

12 need support and psychological need satisfaction within the physical education context.

13 Keywords: Validation, psychological need support, psychological need satisfaction, self-

14 determination theory, physical education. 
Assessing perceived need support and need satisfaction in school physical education: Initial validity evidence with English-speaking adolescents levels of physical activity and are a growing focus of concern (e.g., Han, Lawlor, \& Kimm, 2010). The World Health Organization (WHO, 2010) states that children and adolescents should engage in 60 minutes or more of moderate-to-vigorous physical activity per day, or vigorous intensity physical activity on at least three days per week in order to maintain or improve health. However, only a small proportion of youth are meeting the recommendations set by the WHO (Hallal et al., 2012). Research has consistently demonstrated that engagement in physical activity is related to positive physiological and psychological outcomes such as reduced risk of obesity, improved cardio-metabolic health, and self-esteem (Ekelund, 2012; Janssen \& LeBlanc, 2010). Levels of engagement in physical activity continue to be low among school aged youth, and evidence supports that active children are more likely to be active adults who lead healthier lives compared to their insufficiently active counterparts (Telama et al., 2005). Therefore, there is a need to further understand the motivational determinants of physical activity participation (or not) in order to optimize a high quality of motivation towards physical activity.

Physical Education (PE) has received much attention as a context in which to combat low levels of physical activity in youth. PE can provide a setting where teachers can encourage children and adolescents to engage in healthy and sustained levels of physical activity. A particular area of focus in the current literature includes the socio-contextual determinants within PE classes (e.g., perceptions of psychological need support), and how students perceive these determinants in relation to sustained engagement (Ntoumanis, 2005; Standage, Gillison, Ntoumanis, \& Treasure, 2012; Taylor \& Ntoumanis, 2007), participation in optional PE (Ntoumanis, 2005), and engagement in physical activity and sport outside of school hours (Sánchez-Oliva, Sánchez-Miguel, Kinnafick, Leo, \& García-Calvo, 2014). Grounded in self-determination theory (SDT; Deci \& Ryan, 2000; Ryan \& Deci, 2017), the purpose of the current study was to evaluate English versions of two instruments that aim to measure 1) students' perceptions of need-supportive behaviors demonstrated by their PE teacher 
and 2) students perceived satisfaction of the psychological needs for autonomy, competence, and relatedness.

\section{Self-determination theory and need-supportive environments in PE}

SDT, a macro-theory of human motivation, has received wide empirical support in the context of PE and physical activity behavior change (Ng et al., 2012; Teixeira, Carraça, Markland, Silva, \& Ryan, 2012), and is a useful framework for understanding the social-contextual factors that influence motivation and engagement. Given the large body of research supporting the positive outcomes of self-determined types of motivation in the context of PE (Van den Berghe, Vansteenkiste, Cardon, Kirk, \& Haerens, 2014), an important line of empirical investigation within SDT is to explore, identify, and test the social climate that supports volition and self-enacted engagement. SDT theorists propose that the social environment is a key element for supporting the three basic psychological need and is effective in facilitating a high-quality motivation and wellness (Deci \& Ryan, 2000).

Basic Psychological Needs Theory (BPNT; Deci and Ryan 2000), a sub-theory within SDT, outlines that the social climate can explain variability in functioning and wellness. For example, a teacher's interpersonal style can influence a student's motivation and thus engagement by nurturing, as opposed to thwarting, the three basic psychological needs. These needs include the need for autonomy (i.e., having a sense of control and volition over ones actions. For example, having a choice over completing a certain task), competence (i.e., feeling effective in being able to realize a chosen task set out by a teacher), and relatedness (i.e., feeling a sense of connectedness within those they value most, such as a teacher or classmates). When a teacher effectively supports the basic psychological need of a student, they also positively impact the quality of motivation, well-being, and facilitate persistence to the target behavior (e.g., physical activity; Barkoukis, Hagger, Lambropoulos, \& Tsorbatzoudis, 2010; Sánchez-Oliva, Sánchez-Miguel, et al., 2014; Standage et al., 2012).

A need-supportive teacher facilitates the satisfaction of autonomy, competence, and relatedness through the provision of autonomy support, competence support, and relatedness support respectively. Autonomy supportive teachers attempt to identify, nurture, and develop a student's interests and goals (Taylor \& Ntoumanis, 2007). They also encourage initiative, acknowledge the students frame of reference, and show empathy towards the student. Competence support has been 
70 defined as the provision of desired information and guidance to enable a student to complete a task

71 effectively and successfully (Sierens, Vansteenkiste, Goossens, Soenens, \& Dochy, 2009). For

72 example, a teacher could give clear guidelines to clarify expectations, offer guidance when a student

73 is engaging in a task, and provide relevant and positive feedback once the task has been completed

with success (Sierens et al., 2009). Relatedness support refers to the degree of involvement of the

teacher in their interaction with the student (i.e., spending a considerable proportion of their time,

energy, and resources with the student; Cox, Duncheon, \& McDavid, 2009). Relatedness support

would also include the way in which the teacher interacts with the student. For example, a teacher

who is supporting relatedness need satisfaction would demonstrate warmth, emotional support, and be responsive to the student (Taylor \& Ntoumanis, 2007).

\section{Measurement of need-supportive environments and basic psychological need satisfaction in PE}

While there have been many attempts to study motivational dynamics within the context of

PE (Rutten, Boen, \& Seghers, 2012; Standage, Duda, \& Ntoumanis, 2005; Taylor \& Lonsdale, 2010; in PE settings is the availability of contextually valid measurement instruments for assessing needsupportive environments and basic psychological need satisfaction. Traditionally, SDT-based research has focused heavily on the assessment of autonomy-supportive environments. A number of measures have been developed and adapted within the PE context in order to examine autonomy support, such as the Health Care Climate Questionnaire (HCCQ; Williams, Grow, Freedman, Ryan, \& Deci, 1996), the Perceived Autonomy Support Scale for Exercise Settings (PASSES; Hagger et al., 2007), and the

91 Learning Climate Questionnaire (LCQ; Williams \& Deci, 1996). However, focusing only on autonomy support underplays the importance of assessing competence-supportive and relatednesssupportive dimensions of the teaching environment (Jang, Reeve, \& Deci, 2010).

To assess the teaching environment from a multi-dimensional perspective (autonomy-, competence-, and relatedness-supportive behaviors), an instrument that has been frequently used is

96 the Teaching as Social Context Questionnaire (TASCQ; Belmont, Skinner, Wellborn, \& Connell, 97 1988). However, although the TASCQ has been used in numerous research studies, the scale was 
98 created for a general education setting and not specific for the PE context. Two scales were recently

99 created in order to assess perceptions of interpersonal behaviors from a multidimensional perspective

100 within the exercise and sport contexts. Firstly, Emm-Collison, Standage, and Gillison (2016)

101 developed the Adolescent Psychological Need Support in Exercise Questionnaire (APNSEQ) aimed

102 to evaluate the adolescents' perceptions of psychological need support for exercise through a three-

103 factor nine-items measure. Secondly, Rocchi, Pelletier, and Desmarais (2017) validated the

104 Interpersonal Behaviors Questionnaire (IBQ), composed by 24 items and six factors aimed to

105 evaluated perceptions of need-supportive and need-thwarting behaviors within the sport context.

106 Unfortunately, these instruments were published after the current data collection was conducted, and

107 thus were not evaluated in the present study.

In the current study, we have evaluated the Basic Psychological Needs Support Questionnaire (BPNSQ). The BPNSQ, a 12-item scale, was specifically developed to measure students' perceptions of teachers' autonomy-, competence-, and relatedness-supportive behaviors. The BPNSQ has previously been validated in a sample of Spanish (Sánchez-Oliva, Leo, Amado, Cuevas, \& GarcíaCalvo, 2013) and Portuguese students (Sánchez-Oliva, Leal, Marreiros, Pulido, \& García-Calvo, 2014), but an English version of the BPNSQ has not yet been evaluated. In these previous studies, the BPNSQ showed an acceptable factorial validity (model fit and factor loading patterns), nomological validity (positive associations with psychological need satisfaction), reliability, and invariance across gender (Sánchez-Oliva et al., 2013, 2014).

Regarding the assessment of basic psychological need satisfaction in PE, Haerens, Aelterman,

118 Vansteenkiste, Soenens, and Van Petegem (2015) validated an adapted version of the Basic

119 Psychological Need Satisfaction and Frustration Scale (BPNSFS: Chen et al., 2015) to examine the

120 satisfaction of the three psychological needs in PE. However, many of the studies that have analyzed

121 the students' psychological need satisfaction with adolescent samples have used the Basic

122 Psychological Needs in Exercise Scale (BPNES: Vlachopoulos \& Michailidou, 2006). One promising

123 line of research is the adaptation and validation of this scale for the physical education context (BPN-

124 PE; Vlachopoulos, Katartzi, \& Kontou, 2011), which we will investigate in the present study. The

125 BPN-PE was developed to examine psychological need satisfaction with Greek-speaking participants 
126 (Vlachopoulos et al., 2011), and translated versions have been used to examine the constructs in Spain

127 (Moreno, González-Cutre, Chillon, \& Parra, 2008), Portugal (Pires, Cid, Borrego, Alves, \& Silva,

128 2010), Germany (Heckmann, 2013), and the Philippines (Cagas \& Hassandra, 2014). Taken together,

129 these studies have provided initial evidence of factorial validity (model fit and factor loading patterns)

130 reliability, and nomological validity (positive associations with perceived autonomy support and

131 subjective vitality) of the BPN-PE. At present, the BPN-PE has not been validated with an English-

132 speaking population thereby limiting the scope to which the measure can be used by research groups

133 globally.

\section{The present study}

135 Given the lack of contextually valid measurement instruments for assessing need-supportive

136 environments and basic psychological need satisfaction with English-speaking adolescents in the PE

137 context, this study aimed to address this gap in the literature. Specifically, the goal of the current

138 study was to examine the psychometric properties of the English language versions of the BPNSQ and

139 BPN-PE with a sample of secondary-age PE students. We hypothesized that: (1) the BPNSQ and

140 BPN-PE would display a good factorial validity (i.e., acceptable fit indices, factor loadings) and

141 discriminant validity (i.e., reasonable interfactor correlations) through a 3-factor model; 2) the

142 instrument subscales would show acceptable internal consistency $(>0.7)$; (3) the BPNSQ and BPN-

143 PE would be invariant across gender; and (4) perceived need support from the teacher would be

144 positively associated with perceived psychological need satisfaction.

\section{Method}

\section{Participants}

147 Following ethical approval by an English University school ethics board, participants were

148 recruited to the current study. Participants comprised 453 secondary school aged students (223 males,

149230 females) aged between 12 and 17 years $(M=13.94 ; S D=1.07)$ from 14 classes within five

150 randomly selected state secondary schools situated in the Midlands region of England.

\section{Measures}

152 Perceived Psychological Need Support. The Basic Psychological Needs Support

153 Questionnaire (BPNSQ; Sánchez-Oliva et al., 2013) was translated into English. The questionnaire 
154

155

156

157

158

159

160

161

162

163

164

contains 12 items (See Appendix 1) followed the statement "In Physical Education classes, my teacher..." as indicators of the three factors: autonomy support (items 1, 4, 7, 10), competence support (items 2, 5, 8, 11) and relatedness support (items 3, 6, 9, 12). Responses were given on a 7-point scale ranging from 1 (strongly disagree) to 7 (strongly agree).

To ensure the quality of translation of the English version, we adopted the backward translation strategy proposed by Hambleton (2005). First, all the items were translated from Spanish into English and subsequently, a separate group of translators translated it back to the original language, Spanish. As we observed a high degree of agreement between both versions, three experts within the field of sport psychology then compared the item content of the translated version with the original scale proceeding to further item modifications. Following this step, we reached a consensus on the final translated version of the scales.

Psychological Need Satisfaction. The English version of the 12-item Basic Psychological Needs in Physical Education Scale (BPN-PE: Vlachopoulos, Katartzi, \& Kontou, 2011) was used to assess students' psychological need satisfaction in PE classes (see Appendix 2). The stem was "In Physical Education classes, my teacher..." and four items represented each of the basic psychological need support: autonomy satisfaction, competence satisfaction and relatedness satisfaction. Each item was measured on a 7-point scale ranging from 1 (strongly disagree) to 7 (strongly agree).

The BPN-PE was developed in Greek (Vlachopoulos et al., 2011) and translated into English when published. However, the psychometric properties of the English version have not been evaluated. A back-translation procedure was used to ensure the quality of translation, involving four English speaking Greek nationals. Two translated from Greek to English, and two from English back to Greek. Then, the meaning of the original items and translated Greek items was compared and the final English translation was agreed (Vlachopoulos et al., 2011).

\section{Procedure}

One of the researchers contacted the head teachers at the randomly selected schools to explain the objectives of the study and to invite the school to participate. PE teachers were informed of the purpose of the study and parental consent was obtained for all participants prior to commencing the study. All participants were treated according to the ethical guidelines of the American Psychological 
182 Association, and the students were informed that their responses would be kept confidential and that

183 they could decline to participate at any time. The questionnaires were administered at the start of a PE

184 lesson during term time, and each student had approximately 25-30 minutes to complete the

185 questionnaires.

186 Data analysis

187 Statistical analyses were conducted using Mplus 7.3 (Muthén \& Muthén, 1998-2017).

188 Confirmatory Factor Analysis (CFA) was used in conjunction with the robust maximum likelihood

189 (MLR) estimator. The small amount of missing data present at the item level $(0.67 \%$ to $2.72 \%$ per

190 item, $M=1.29 \%$ ) was handled with Full Information Maximum Likelihood (FIML) estimation

191 (Enders, 2010). To assess model fit we used the comparative fit index (CFI), the Tucker-Lewis Index

192 (TLI), the standardized root mean residual (SRMR), and the root mean square error of approximation

193 (RMSEA). Traditional cut off criteria with CFI and TLI values around 0.90, and SRMR and RMSEA

194 values around 0.08 were used to indicate acceptable fit (Marsh, 2007). We also used the Akaike

195 Information Criterion (AIC), the Bayesian Information Criterion (BIC), and the sample size adjusted

196 BIC (ABIC) where a model with lower values relative to other models suggest a better model fit.

197 Also, we assessed Cronbach's alpha, average variance extracted, and composite reliability to evaluate

198 internal consistency.

199 Furthermore, in order to analyze the nomological validity of both constructs, we estimated the

200 correlations between latent factors based on the final retained solutions obtained in the previous

201 analysis. Lastly, the measurement of invariance across gender within the best model was tested

202 through the following models: (1) Configural Invariance, where the baseline model was tested

203 simultaneously for males and females with no equality constraints; (2) Weak Invariance, in which all

204 factor loadings were constrained to equality across groups; (3) Strong Invariance, in which the factor

205 loadings and items' intercepts were constrained to be equal across groups; and (4) Strict Invariance,

206 where the factor loadings, items' intercepts, and items' uniquenesses were constrained to equality

207 across groups. In the strong and strict invariance models, the latent means were freely estimated in the

208 second group. According to Chen (2007), in the comparison of nested models, a decrease lower than 
2090.01 on the CFI and TLI, or 0.015 on the RMSEA, are considered to provide an equivalent level of fit 210 to the data.

\section{Results}

\section{The Basic Psychological Needs Support Questionnaire (BPNSQ)}

The Goodness-of-fit statistics and information criteria of the models estimated for the BPNSQ are displayed in Table 1. The 3-factors CFA provided an acceptable model fit (CFI and TLI > 0.900; SRMR and RMSEA < 0.080). Furthermore, Table 2 details the standardized factor loadings and the

$R^{2}$ of the items in the models tested for the BPNSQ. For the 3-factors CFA, all factors were well

234 CFA solution also provided acceptable scores of internal consistency (Cronbach's alphas greater than 2350.80 , composite reliability greater than 0.80 , and average variance extracted greater than 0.50 ).

\section{Invariance Analysis}


The next step was to test the invariance across gender by using the best model obtained in the

238 previous step (i.e., single-factor CFA for need support and 3-factor CFA for need satisfaction). The

239 Goodness-of-fit statistics and information criteria of the four models estimated are detailed in Table 4.

240 In both scales, the configural invariance model (with no constraints) showed an acceptable fit to the

241 data for males and females (CFI and TLI > 0.900; RMSEA and SRMR < 0.080). Weak, strong, and

242 strict invariance were supported as no substantial worsening in the model fit indices were observed

243 with increasing constraints $(\triangle \mathrm{CFI}$ and $\triangle \mathrm{TLI}<0.01$, and $\triangle \mathrm{RMSEA}<0.015)$.

\section{Nomological Validity}

245 A secondary purpose of the present study was to test the nomological validity of both

246 measures through latent factor correlations. Based on the findings in the previous analyses, we used

247 the single-factor CFA solution of the BPNSQ and the 3-factors CFA solution of the BPN-PE. When

248 using the single-factor CFA solution of the BPNSQ, the global need support was highly and positively

249 associated with competence, relatedness, and autonomy satisfaction $\left(r_{\text {competence }}=0.626 ; r_{\text {relatedness }}=\right.$

$\left.250 \quad 0.867 ; r_{\text {autonomy }}=0.759 ; \mathrm{p}<0.01\right)$.

251

\section{Discussion}

252 This study aimed to analyze the psychometric properties of two scales developed to assess pupils'

253 perceptions of teachers' need-supportive behaviors and psychological need satisfaction within the PE

254 context. Although the scales have previously been validated in several languages, the current study

255 includes a validation of English versions of these instruments. The findings provide initial

256 psychometric support of the English version of the BPNSQ and BPN-PE among PE students, and also

257 suggest several areas of improvements.

258 The Basic Psychological Needs Support Questionnaire (BPNSQ)

259 The first aim of the present study was to evaluate the factorial validity of both scales. For the 260 BPNSQ, the 3-factors CFA showed an acceptable fit to the data (CFI and TLI > 0.900, RMSEA and

261 SRMR $<0.060)$ and high and significant factor loadings $(\lambda>0.600)$. However, the strong inter-factor

262 correlations among the need support factors ( $r$ ranged from 0.908 to 1.008) questions the discriminant

263 validity of the specific dimensions, and therefore we cannot fully support our first hypothesis relating 
264 to the BPNSQ. The strong inter-factor correlations between need-supportive factors within a CFA

265 framework have been highlighted in previous research. For example, previous validations of the

266 BPNSQ (Sánchez-Oliva et al., 2013; Sánchez-Oliva et al., 2014) also reported strong factor

267 correlations ( $r$ between 0.700 and 0.920 for the Spanish validation and $r$ between 0.740 and 0.920 for

268 the Portuguese validation). Furthermore, Stenling, Ivarsson, Hassmén, and Lindwall (2015) reported

269 correlations between factors capturing athletes' perceptions of coaches' need-supportive behaviors

270 greater than 0.950, and Appleton et al. (2016) found correlations between the three supportive factors

271 within their questionnaire (task-involving, autonomy-supportive, and social support) greater than

2720.850.

273 The very strong inter-factor correlations found for the 3-factors CFA indicates that further

274 research is needed to evaluate if the specific factors measuring psychological need support can be

275 distinguished. As stated by Kline (2016), variables correlating greater than 0.90 cannot be said to

276 measure different constructs. Overall, these findings suggest that specific factors of the BPNSQ did

277 not distinguish, and refinement of this scale (e.g., rewording of items) may be neccesary to be able to

278 distinguish between the three sub-dimensions. Several reasons could explain these high inter-factor

279 correlations. First, from a psychometric perspective, in the 3-factor CFA model cross-loadings on

280 non-target factors are fixed to 0 , which often results in inflated factor correlations. Second, from a

281 theoretical point of view, the strategies to promote autonomy, competence, and relatedness are highly

282 interconnected (Jang et al., 2010; Vansteenkiste et al., 2012). For example, when a teacher provides

283 freedom to make decisions during a given task (autonomy-supportive strategy), the student will feel

284 that the teacher is also promoting his/her competence. The child could interpret this as the teacher

285 allowing them autonomy and promoting a sense of competence because he/she perceives them as

286 capable to perform the task through active learning. Similarly, if a teacher considers the students'

287 opinion about a given task (autonomy support strategy), the student may interpret this behavior as a

288 form of relatedness support. It is therefore important in future research to develop measures that make

289 it possible to distinguish between sub-dimensions in multidimensional scales of psychological need

290 support. Therefore, although we found that a single-factor CFA of the BPNSQ provided an adequate 
291 fit to the data for this particular sample of PE students, we recommend that future studies continue to

292 explore the psychometric properties of the 3-factor model.

293 The Basic Psychological Need in Physical Education Scale (BPN-PE)

294 The 3-factor CFA model for the BPN-PE did adequately capture the underlying factor

295 structure, with acceptable scores in the model fit (CFI and TLI $>0.900$, RMSEA and SRMR $<0.060$ ),

296 standardized solution $(\lambda>0.600)$, and inter-factor correlations ranging from 0.677 to 0.831 . Overall,

297 the results from the current study indicate that a multidimensional measurement model provides a

298 reasonable approximation to the data for the BPN-PE. These findings support our hypothesis, and are

299 in line with the main tenants of SDT that adolescents perceive autonomy, competence, and relatedness

300 satisfaction as three distinct psychological nutrients (Deci \& Ryan, 2000). During the initial validation

301 of the BPNES, Vlachopoulos and Michailidou (2006) compared different representations (a single-

302 factor model, three 2-factor models, and a 3-factor model) and highlighted the 3-factor model as a

303 better representation compared to the other solutions. A 3-factor model was also supported in the

304 Portuguese validation of the BPNES (Moutão, Serra, Alves, Leitão, \& Vlachopoulos, 2012).

305 Invariance analysis

306 Another goal of the present study was to test if both scales were invariant across gender. The

307 findings supported the hypothesis as no substantial changes in the fit indices were observed with

308 increasing equality constraints. Overall, the result suggests that the measurement models of the

309 English version of the BPNSQ and the BPN-PE are fully invariant across gender. With respect to the

310 BPNSQ, the current study is in line with previous research that demonstrated invariance across gender

311 in the Spanish and Portuguese versions (Sánchez-Oliva et al., 2013; Sánchez-Oliva et al., 2014).

312 Vlachopoulos et al., (2011) also demonstrated configural, weak, strong, and strict invariances of the

313 BPN-PE in a sample of Greek students. Our results demonstrate that the underlying measurement

314 structure of the scale (i.e., factor loadings, intercepts, and uniquenesses) is similar for males or

315 females, which allows for meaningful mean comparisons between males and females. This also has

316 practical implications as both questionnaires can be administered regardless of the students' gender.

317 However, we encourage future research to replicate these findings in younger and older students.

\section{Nomological validity}


We also analyzed the nomological validity of each construct by using correlations between

the single-factor CFA solution of perceived psychological need support and the 3-factor CFA

representation of psychological need satisfaction. Results showed that both the global psychological

need support was positively associated with autonomy, competence, and relatedness satisfaction. That

is, those pupils who perceived that their PE teacher dedicated resources to promoting psychological need satisfaction reported greater scores of autonomy, competence, and relatedness satisfaction. Overall, these findings provide support for the hypothesis, and thus provide initial support for the al., 2014; Standage et al., 2005).

nomological validity of the scales. Findings are in line with previous studies that show the importance of a psychological need-supportive learning environment to promote autonomy, competence, and relatedness need satisfaction among students (Ntoumanis, 2005; Sánchez-Oliva, Sánchez-Miguel, et

\section{Limitations and future research}

The current study presents limitations to be considered in future studies. First, the data were cross-sectional, and therefore we did not examine changes over time. Future studies could test invariance across time to evaluate if both scales remain invariant over time. Furthermore, the possible underestimation of standard errors because of nesting of students within classes was not accounted for. Future research should also consider the predictive ability of both scales alongside variables related to maladaptive motivation (need thwarting and need frustration), as well as other well-being and performance indicators. Also, future research should perform cross-cultural validation to analyze whether these scales work equally well in different countries. Lastly, the current study tested firstorder solutions, whereas future studies could test different ways to capture the structure of these scales, such as exploratory structural equation modeling, hierarchical models, or bifactor models.

\section{Conclusions}

346 Furthermore, a 3-factor CFA model was found to be an adequate representation of the BPN-PE. 
347 However, our results do not necessarily provide a conclusive answer regarding the nature of the

348 underlying factor structure of these scales, and we recommend that researchers test different ways

349 (within both CFA and ESEM frameworks) to capture the structure of both scales. In conclusion, the

350 present study proposes the English version of both the BPNSQ and BPN-PE as viable tools to

351 measure perceived psychological need support and perceived psychological need satisfaction within 352 the context of PE. 
353

\section{References}

Appleton, P. R., Ntoumanis, N., Quested, E., Viladrich, C., \& Duda, J. L. (2016). Initial validation of the coach-created Empowering and Disempowering Motivational Climate Questionnaire (EDMCQ-C). Psychology of Sport and Exercise, 22, 53-65.

Barkoukis, V., Hagger, M. S., Lambropoulos, G., \& Tsorbatzoudis, H. (2010). Extending the transcontextual model in physical education and leisure-time contexts: Examining the role of basic psychological need satisfaction. British Journal of Educational Psychology, 80, 647-670.

Bartholomew, K. J., Ntoumanis, N., Ryan, R. M., \& Thøgersen-Ntoumani, C. (2011). Psychological need thwarting in the sport context: Assessing the darker side of athletic experience. Journal of Sport \& Exercise Psychology, 33, 75-102.

Belmont, M. J., Skinner, E. A., Wellborn, J., \& Connell, J. (1988). Teacher as social context: A measure of student perceptions of teacher provision of involvement, structure and autonomy support. Rochester, NY: University of Rochester.

Cagas, J., \& Hassandra, M. (2014). The Basic Psychological Needs in Physical Education Scale in Filipino: An Exploratory Factor Analysis. Philippine Journal of Psychology, 47, 19-40.

Chen, B., Vansteenkiste, M., Beyers, W., Boone, L., Deci, E. L., Van der Kaap-Deeder, J., ... Verstuyf, J. (2015). Basic psychological need satisfaction, need frustration, and need strength across four cultures. Motivation and Emotion, 39, 216-236.

Chen, F. F. (2007). Sensitivity of goodness of fit indexes to lack of measurement invariance. Structural Equation Modeling: A Multidisciplinary Journal, 14(3), 464-504. http://doi.org/10.1080/10705510701301834

Chen, F., Bollen, K. A., Paxton, P., Curran, P. J., \& Kirby, J. B. (2001). Improper solutions in structural equation models causes, consequences, and strategies. Sociological Methods \& Research, 29, 468-508.

Cox, A., Duncheon, N., \& McDavid, L. (2009). Peers and teachers as sources of relatedness perceptions, motivation, and affective responses in physical education. Research Quarterly for Exercise and Sport, 80, 765-773. 
380

381

382

383

384

385

386

387

388

389

390

391

392

393

394

395

396

397

398

399

400

401

402

403

404

405

406

407

Deci, E. L., \& Ryan, R. M. (2000). The "What" and "Why" of Goal Pursuits: Human Needs and the Self-Determination of Behavior. Psychological Inquiry, 11, 227-268.

Ekelund, U. (2012). Moderate to vigorous physical activity and sedentary time and cardiometabolic risk factors in children and adolescents. JAMA, 307, 704-712.

Emm-Collison, L. G., Standage, M., \& Gillison, F. B. (2016). Development and Validation of the Adolescent Psychological Need Support in Exercise Questionnaire. Journal of Sport and Exercise Psychology, 38(5), 505-520.

Enders, C. K. (2010). Applied missing data analysis. New York: Guilford.

Gignac, G. E. (2016). The higher-order model imposes a proportionality constraint: That is why the bifactor model tends to fit better. Intelligence, 55, 57-68.

Haerens, L., Aelterman, N., Vansteenkiste, M., Soenens, B., \& Van Petegem, S. (2015). Do perceived autonomy-supportive and controlling teaching relate to physical education students' motivational experiences through unique pathways? Distinguishing between the bright and dark side of motivation. Psychology of Sport and Exercise, 16, 26-36.

Hagger, M. S., Chatzisarantis, N. L. D., Hein, V., Pihu, M., Soós, I., \& Karsai, I. (2007). The perceived autonomy support scale for exercise settings (PASSES): Development, validity, and cross-cultural invariance in young people. Psychology of Sport and Exercise, 8, 632-653.

Hallal, P. C., Andersen, L. B., Bull, F. C., Guthold, R., Haskell, W., Ekelund, U., ... Wells, J. C. (2012). Global physical activity levels: Surveillance progress, pitfalls, and prospects. The Lancet, 380, 247-257.

Hambleton, R. K. (2005). Issues, designs and technical guidelines for adapting tests into multiple languages and cultures. In R. K. Hambleton, P. F. Merenda, \& S. D. Spielberger (Eds.), Adapting educational and psychological tests for cross-cultural assessment (pp. 3-38). New Jersey: Lawrence Erlbaum Associates.

Han, J. C., Lawlor, D. A., \& Kimm, S. Y. (2010). Childhood obesity. The Lancet, 375, 1737-1748. Heckmann, P. (2013). Adaptation and validation of the German version of the Basic Psychological Needs in Physical Eduation scale. University of Jyväskylä.

Jang, H., Reeve, J., \& Deci, E. L. (2010). Engaging students in learning activities: It is not autonomy 
support or structure but autonomy support and structure. Journal of Educational Psychology, $102,588-600$.

Janssen, I., \& LeBlanc, A. G. (2010). Systematic review of the health benefits of physical activity and fitness in school-aged children and youth. International Journal of Behavioral Nutrition and Physical Activity, 7, 40-55.

John, O., \& Benet-Martínez, V. (2000). Measurement: Reliability, Construct Validation, and Scale Construction. In H. T. Reis \& C. M. Judd (Eds.), Handbook of research methods in social and personality psychology (pp. 339-369). Cambridge: Cambridge University Press.

Jöreskog, K. G. (1999). How large can a standardized coefficient be? Unplublished Report. SSI Central, Inc. Retrieved from http://www.ssicentral.com/lisrel/techdocs/HowLargeCanaStandardizedCoefficientbe.pdf

Kline, R. B. (2016). Principles and practice of structural equation modeling (4th ed.). New York, NY: Guilford Press.

Marsh, H. W. (2007). Application of confirmatory factor analysis and structural equation modeling in sport/exercise psychology. In G. T. and R. C. Eklund (Ed.), Handbook of Sport Psychology 3rd Edn (pp. 774-798). Hoboken, NJ: Wiley.

McDonald, R. P. (1999). Test theory: A unified treatment. Psychology Press.

Moreno, J. A., González-Cutre, D., Chillon, M., \& Parra, N. (2008). Adaptación a la educación física de la Escala de las Necesidades Psicológicas Básicas en el ejercicio [Adaptation of the basic Psychological Needs in Exercise Scale to physical education]. Revista Mexicana de Psicología, 25, 295-303.

Moutão, J. M. R. P., Serra, L. F. C., Alves, J. A. M., Leitão, J. C., \& Vlachopoulos, S. P. (2012). Validation of the Basic Psychological Needs in Exercise Scale in a Portuguese sample. The Spanish Journal of Psychology, 15, 399-409.

Muthén, L. K., \& Muthén, B. O. (1998-2017). Mplus user's guide. Eighth Edition. Los Angeles, CA: Muthén \& Muthén.

Ng, J. Y. Y., Ntoumanis, N., Thogersen-Ntoumani, C., Deci, E. L., Ryan, R. M., Duda, J. L., \& Williams, G. C. (2012). Self-Determination Theory Applied to Health Contexts: A Meta- 
Analysis. Perspectives on Psychological Science, 7, 325-340.

\section{7}

438

Ntoumanis, N. (2005). A prospective study of participation in optional school physical education using a self-determination theory framework. Journal of Educational Psychology, 97, 444-453.

Pires, A., Cid, L., Borrego, C., Alves, J., \& Silva, C. (2010). Validação preliminar de um questionário para avaliar as necessidades psicológicas básicas em Educação Física [Preliminary validation of a questionnaire to measure basic psychological needs in Physical Education]. Motricidade, 6, $33-51$.

Rocchi, M., Pelletier, L., \& Desmarais, P. (2017). The Validity of the Interpersonal Behaviors Questionnaire (IBQ) in Sport. Measurement in Physical Education and Exercise Science, 21(1), $15-25$.

Rutten, C., Boen, F., \& Seghers, J. (2012). How school social and physical environments relate to autonomous motivation in physical education: The mediating role of need satisfaction. Journal of Teaching in Physical Education, 31, 216-230.

Ryan, R. M., \& Deci, E. L. (2017). Self-determination theory: Basic psychological needs in motivation, development, and wellness. Guilford Publications.

Sánchez-Oliva, D., Leal, J., Marreiros, J., Pulido, J. J., \& García-Calvo, T. (2014). Validação do Questionário de Apoio às Necessidades Psicológicas Básicas em Portugal [Validation of the Basic Psychological Needs Questionnaire in Portugal]. Psicologia Reflexão E Crítica, 27, 615624.

Sánchez-Oliva, D., Leo, F. M., Amado, D., Cuevas, R., \& García-Calvo, T. (2013). Desarrollo y validación del cuestionario de apoyo a las necesidades psicológicas básicas en educación física [Development and validation of the questionnarie of basic psychological need support in physical education]. Motricidad. European Journal of Human Movement, 30, 53-71.

Sánchez-Oliva, D., Morin, A. J. S., Teixeira, P. J., Carraça, E. V., Palmeira, A. L., \& Silva, M. N. (2017). A bifactor exploratory structural equation modeling representation of the structure of the basic psychological needs at work scale. Journal of Vocational Behavior, 98, 173-187.

Sánchez-Oliva, D., Sánchez-Miguel, P. A., Kinnafick, F.-E., Leo, F. M., \& García-Calvo, T. (2014). 
Sierens, E., Vansteenkiste, M., Goossens, L., Soenens, B., \& Dochy, F. (2009). The synergistic relationship of perceived autonomy support and structure in the prediction of self-regulated learning. British Journal of Educational Psychology, 79, 57-68.

Standage, M., Duda, J. L., \& Ntoumanis, N. (2005). A test of Self-Determination Theory in school physical education. British Journal of Educational Psychology, 75, 411-433.

Standage, M., Gillison, F., Ntoumanis, N., \& Treasure, D. C. (2012). Predicting students' physical activity and health-related well-being: A prospective cross-domain investigation of motivation across school physical education and exercise settings. Journal of Sport \& Exercise Psychology, $34,37-60$.

Stenling, A., Ivarsson, A., Hassmén, P., \& Lindwall, M. (2015). Using bifactor exploratory structural equation modeling to examine global and specific factors in measures of sports coaches' interpersonal styles. Frontiers in Psychology, 6(1303).

Taylor, I. M., \& Lonsdale, C. (2010). Cultural differences in the relationships among autonomy support, psychological need satisfaction, subjective vitality, and effort in British and Chinese physical education. Journal of Sport \& Exercise Psychology, 32, 655-673.

Taylor, I. M., \& Ntoumanis, N. (2007). Teacher motivational strategies and student self-determination in physical education. Journal of Educational Psychology, 99, 747-760.

Teixeira, P. J., Carraça, E. V, Markland, D., Silva, M. N., \& Ryan, R. M. (2012). Exercise, physical activity, and self-determination theory: A systematic review. International Journal of Behavioral Nutrition and Physical Activity, 9, 78-99.

Telama, R., Yang, X., Viikari, J., Välimäki, I., Wanne, O., \& Raitakari, O. (2005). Physical activity from childhood to adulthood. American Journal of Preventive Medicine, 28, 267-273.

Van den Berghe, L., Vansteenkiste, M., Cardon, G., Kirk, D., \& Haerens, L. (2014). Research on self-determination in physical education: Key findings and proposals for future research. Physical Education \& Sport Pedagogy, 19, 97-121. 
490

491

492

493

494

495

496

497

498

499

500

501

502

503

504

505

506

507

508

509

510

511

van Knippenberg, D., \& Sitkin, S. B. (2013). A Critical Assessment of CharismaticTransformational Leadership Research: Back to the Drawing Board? The Academy of Management Annauls, 7, 1-60.

Vansteenkiste, M., Sierens, E., Goossens, L., Soenens, B., Dochy, F., Mouratidis, A., ... Beyers, W. (2012). Identifying configurations of perceived teacher autonomy support and structure: Associations with self-regulated learning, motivation and problem behavior. Learning and Instruction, 22, 431-439. http://doi.org/10.1016/j.learninstruc.2012.04.002

Vlachopoulos, S. P., Katartzi, E. S., \& Kontou, M. G. (2011). The Basic Psychological Needs in Physical Education Scale. Journal of Teaching in Physical Education, 30, 263-280.

Vlachopoulos, S. P., \& Michailidou, S. (2006). Development and anitial validation of a measure of autonomy, competence, and relatedness in exercise: The basic psychological needs in exercise scale. Measurement in Physical Education and Exercise Science, 10, 179-201.

World Health Organization. (2010). Global Recommendations on Physical Activity for Health. Geneva, World Health Organization.

Williams, G. C., \& Deci, E. L. (1996). Internalization of biopsychosocial values by medical students: A test of self-determination theory. Journal of Personality and Social Psychology, 70, 767-779.

Williams, G. C., Grow, V. M., Freedman, Z. R., Ryan, R. M., \& Deci, E. L. (1996). Motivational Predictors of Weight Loss and Weight-Loss Maintenance. Journal of Personality and Social Psychology, 70, 115-126.

Zhang, T., Solmon, M. A., Kosma, M., Carson, R. L., \& Gu, X. (2011). Need support, need satisfaction, intrinsic motivation, and physical activity participation among middle school students self-determination theory. Journal of Teaching in Physical Education, 30, 51-68. 
1

2

3

4

5

6

7

8

9
5

6

\section{Appendix 1. The Basic Psychological Needs Support Questionnaire (BPNSQ)}

In Physical Education classes, my teacher...

1. Often asks us about our preferences with respect to the activities we carry out.

2. Encourages us to trust our ability to carry out the tasks well.

3. Promotes good relationships between classmates at all times.

4. Attempts to give us some freedom when it comes to performing the tasks.

5. Offers us activities based on our skill level.

6. Encourages positive interactions among all pupils.

7. Considers our opinion about the activities we perform in the class.

8. Always tries to help us achieve our goals for specific activities.

9. Promotes involvement of all pupils taking part in the activities.

10. Encourages us to make decisions when carrying out tasks.

11. Promotes pupil learning and improvement in the activities.

12. Helps us to solve problems within the class in a supportive manner.

Autonomy Support $=$ items 1, 4, 7, and 10; Competence support $=$ items 2, 5, 8, and 11; Relatedness Support $=$ items 3, 6, 9, and 12 .

\section{Appendix 2. The Basic Psychological Needs in Physical Education Scale (BPN-PE)}

In general, in Physical Education...

1. I feel that I improve even in tasks considered difficult by most of the children.

2. My relationships with my classmates are very friendly.

3. We do things that are of interest to me.

4. I feel I perform well even the tasks are considered difficult by most of the children.

5. I feel I have a close bond with my classmates.

6. I feel that Physical Education is taught is the way I would like it to be taught.

7. I feel I do very well even in the tasks considered difficult by most of the children.

8. I feel a valued member of a group of close friends.

9. I feel lessons are taught in ways I completely agree with.

10. I am able to succeed even in the tasks considered difficult by most of the children.

11. I feel I belong to the group of my classmates.

12. I feel the activities we are doing have been chosen by me.

Competence Satisfaction $=$ items 1, 4, 7, and 10; Relatedness Satisfaction $=$ items 2, 5, 8, and 11;

Autonomy Satisfaction $=$ items 3, 6, 9, and 12 . 
Table 1. Goodness-of-fit statistics and information criteria for the models estimated.

\begin{tabular}{lccccccccccc}
\hline Model & $X^{2}$ & $p$ & $d f$ & CFI & TLI & SRMR & RMSEA [90\% CI $]$ & AIC & BIC & ABIC \\
\hline \multicolumn{70}{c}{ The Basic Psychological Needs Support Questionnaire (BPNSQ) } \\
\hline 3-Factors CFA & 125.178 & 0.000 & 51 & 0.960 & 0.949 & 0.035 & $0.057[0.044-0.070]$ & 15769.116 & 15929.203 & 15805.433 \\
Single-factor CFA & 150.608 & 0.000 & 54 & 0.948 & 0.937 & 0.038 & $0.063[0.051-0.075]$ & 15809.956 & 15957.729 & 15843.479 \\
\hline
\end{tabular}

The Basic Psychological Needs in Physical Education Scale (BPN-PE)

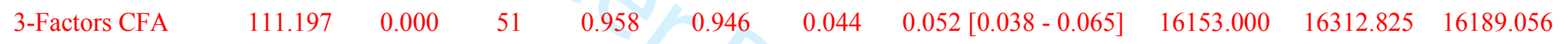

\section{9}


Table 2. Standardized factor loadings of the 3-Factor CFA solution and Single-Factor CFA of the BPNSQ.

\begin{tabular}{|c|c|c|c|c|c|c|}
\hline \multirow[b]{2}{*}{ Items } & \multicolumn{4}{|c|}{ 3-Factors CFA } & \multicolumn{2}{|c|}{ Single-Factor CFA } \\
\hline & $\begin{array}{c}\text { Autonomy } \\
\text { Support }\end{array}$ & $\begin{array}{c}\text { Competence } \\
\text { Support }\end{array}$ & $\begin{array}{c}\text { Relatedness } \\
\text { Support }\end{array}$ & $\mathrm{R}^{2}$ & $\begin{array}{l}\text { Global } \\
\text { factor }\end{array}$ & $\mathrm{R}^{2}$ \\
\hline 1 & $0.719 * *$ & & & $0.517 * *$ & $0.691 * *$ & $0.478 * *$ \\
\hline 4 & $0.752 * *$ & & & $0.565 * *$ & $0.747 * *$ & $0.558 * *$ \\
\hline 7 & $0.711 * *$ & & & $0.505^{* *}$ & $0.674 * *$ & $0.455^{* *}$ \\
\hline 10 & $0.805^{* *}$ & & & $0.648 * *$ & $0.790 * *$ & $0.624 * *$ \\
\hline 2 & & $0.816^{* *}$ & & $0.666^{* *}$ & $0.802 * *$ & $0.643 * *$ \\
\hline 5 & & $0.671 * *$ & & $0.450 * *$ & $0.663 * *$ & $0.439 * *$ \\
\hline 8 & & $0.820 * *$ & & $0.672 * *$ & $0.801 * *$ & $0.642 * *$ \\
\hline 11 & & $0.810 * *$ & & $0.657 * *$ & $0.789 * *$ & $0.623 * *$ \\
\hline 3 & & & $0.744 * *$ & $0.553 * *$ & $0.759 * *$ & $0.576^{* *}$ \\
\hline 6 & & & $0.733 * *$ & $0.538 * *$ & $0.751 * *$ & $0.564 * *$ \\
\hline 9 & & & $0.691 * *$ & $0.478 * *$ & $0.692 * *$ & $0.479 * *$ \\
\hline 12 & & & $0.770 * *$ & $0.592 * *$ & $0.784 * *$ & $0.615^{* *}$ \\
\hline$\alpha$ & 0.835 & 0.854 & 0.820 & & 0.936 & \\
\hline $\mathrm{CR}$ & 0.835 & 0.862 & 0.824 & & 0.938 & \\
\hline AVE & 0.559 & 0.611 & 0.540 & & 0.558 & \\
\hline
\end{tabular}

${ }^{*} p<0.05 ; * * p<0.01 ;$ Note: $\alpha=$ Cronbach's alpha. $\mathrm{CR}=$ Composite Reliability. AVE = Average Variance Extracted. 
Table 3. Standardized factor loadings of the 3-Factor CFA solution of the BPN-PE.

\begin{tabular}{|c|c|c|c|c|}
\hline Items & $\begin{array}{l}\text { Autonomy } \\
\text { Satisfaction }\end{array}$ & $\begin{array}{l}\text { Competence } \\
\text { Satisfaction }\end{array}$ & $\begin{array}{l}\text { Relatedness } \\
\text { Satisfaction }\end{array}$ & $\mathrm{R}^{2}$ \\
\hline 3 & $0.708^{* *}$ & & & $0.501 * *$ \\
\hline 6 & $0.836^{* *}$ & & & $0.698 * *$ \\
\hline 9 & $0.828 * *$ & & & $0.686^{* *}$ \\
\hline 12 & $0.845^{* *}$ & & & $0.715 * *$ \\
\hline 1 & & $0.799 * *$ & & $0.638 * *$ \\
\hline 4 & & $0.870 * *$ & & $0.757 * *$ \\
\hline 7 & & $0.666^{* *}$ & & $0.444 * *$ \\
\hline 10 & & $0.757 * *$ & & $0.573 * *$ \\
\hline 2 & & & $0.772 * *$ & $0.596 * *$ \\
\hline 5 & & & $0.748 * *$ & $0.559 * *$ \\
\hline 8 & & & $0.794 * *$ & $0.631 * *$ \\
\hline 11 & & D & $0.563 * *$ & $0.317 * *$ \\
\hline$\alpha$ & 0.876 & 0.856 & 0.806 & \\
\hline $\mathrm{CR}$ & 0.881 & 0.858 & 0.814 & \\
\hline AVE & 0.650 & 0.603 & 0.526 & \\
\hline
\end{tabular}


Table 4. Goodness-of-fit statistics and information criteria for the models estimated.

\begin{tabular}{|c|c|c|c|c|c|c|c|c|c|c|}
\hline Model & $X^{2}$ & $p$ & $d f$ & CFI & TLI & SRMR & RMSEA $[90 \% \mathrm{CI}]$ & AIC & $\mathrm{BIC}$ & $\mathrm{ABIC}$ \\
\hline \multicolumn{11}{|c|}{ The Basic Psychological Needs Support Questionnaire (BPNSQ). Single-Factor Solution } \\
\hline Configural Invariance & 257.264 & 0.000 & 107 & 0.927 & 0.910 & 0.047 & $0.079[0.067-0.092]$ & 15816.255 & 16115.905 & 15884.232 \\
\hline Weak Invariance & 276.091 & 0.000 & 119 & 0.924 & 0.916 & 0.056 & 0.077 [0.065- 0.089] & 15805.213 & 16055.605 & 15862.016 \\
\hline Strong Invariance & 294.178 & 0.000 & 131 & 0.921 & 0.921 & 0.059 & $0.075[0.063-0.086]$ & 15794.849 & 15995.984 & 15840.477 \\
\hline Strict Invariance & 293.218 & 0.000 & 130 & 0.921 & 0.920 & 0.058 & $0.075[0.063-0.086]$ & 15796.525 & 16001.765 & 15843.085 \\
\hline \multicolumn{11}{|c|}{ The Basic Psychological Needs in Physical Education Scale (BPN-PE). 3-factors CFA Solution } \\
\hline Configural Invariance & 179.924 & 0.000 & 102 & 0.951 & 0.937 & 0.054 & $0.059[0.044-0.072]$ & 16095.530 & 16415.180 & 16167.641 \\
\hline Weak Invariance & 195.316 & 0.000 & 113 & 0.949 & 0.940 & 0.061 & $0.057[0.043-0.071]$ & 16090.262 & 16364.833 & 16152.204 \\
\hline Strong Invariance & 214.622 & 0.000 & 123 & 0.943 & 0.939 & 0.068 & $0.058[0.045-0.071]$ & 16090.688 & 16324.278 & 16143.385 \\
\hline Strict Invariance & 214.622 & 0.000 & 123 & 0.943 & 0.939 & 0.068 & $0.058[0.045-0.071]$ & 16090.688 & 16324.278 & 16143.385 \\
\hline
\end{tabular}

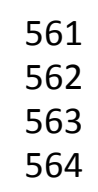


Reviewer: 1

\section{General comments}

I have now read the revised manuscript describing the initial validation of the Basic Psychological Needs Support Questionnaire (BPNSQ) and the Basic Psychological Needs in Physical Education Scale (BPN-PE) scores among English-speaking adolescents. The authors have followed the reviewers' guidelines to a great extent but not all important comments have been satisfied.

In addition, the final picture of the manuscript looks less than promising given the results of the present investigation and the implications of the findings for the applied researcher.

Another observation is that the authors have not clearly and totally moved from their initial conceptualization of writing the paper to the newer perspective suggested by the reviewers. This can be concluded by looking at the study hypotheses. For instance hypothesis \#2 states that "ESEM models...would show a better fit to the data...compared with CFA models" (p 6, L 146). One can see that the authors did not begin with attempting to examine each scale separately and independently but a preoccupation is evident with using ESEM, a part of the previous way of conceptualizing the paper simply emphasizing the statistics rather than the essence of the paper for the applied researcher.

Specific comments

1.Specifically, and with regard to the Basic Psychological Needs Support Questionnaire the results of the present investigation do not provide support for the psychometric properties of the scores derived from the scale. The authors have concluded that a single factor model is the best representation of the structure of the BPNSQ scores (p. 17, L 440; p. 1, L 7). This is problematic given that a single factor model representation of scale scores is against the theory where three factors are proposed to exist. Such a finding seriously limits the value of the present manuscript in the extant literature.

In relation to the Basic Psychological Needs in Physical Education Scale support was obtained for the three-factor structure of the scale based on the standard CFA procedures.

We agree with the reviewer that the single-factor solution of the BPNSQ is against the hypothesis and theory, as well as against previous studies who also used this scale (Sánchez-Oliva, Leal, Marreiros, Pulido, \& García-Calvo, 2014; Sánchez-Oliva, Leo, Amado, Cuevas, \& García-Calvo, 2013). However, in the scientific area the results do not always show what you expect to find, and in our opinion, this aspect is important to highlight in science.

In the current study, it is clear that we expected to find an acceptable psychometric property for the 3-factors-CFA model. The acceptable scores were confirmed with respect to the model fit and factor loadings. However, we found interfactor correlations higher that we expected. Taking into account the results that we found, as the editor said: "It would be silly for any psychometric investigation to 
not highlight the complete lack of discriminant validity of the questionnaire given these numbers". Given these results, we cannot accept to propose the 3-factor-CFA model as the best solution, and we had to test another alternative model (i.e., single-factor solution).

In this regard, as we explain during the discussion, the lack of discriminant validity (i.e., interfactor correlations) has been a relatively common issue in previous studies where a perceived need support scale was tested. Several previous studies used the need-support measure as a single factor (Ntoumanis, 2005; Rutten, Boen, \& Seghers, 2012; Sánchez-Oliva, Sánchez-Miguel, Kinnafick, Leo, \& García-Calvo, 2014; Standage, Duda, \& Ntoumanis, 2005; Zhang, Solmon, Kosma, Carson, \& Gu, 2011).

Therefore, given the results that we found, we only can:

1. To test the 3-factor-CFA model.

2. Given the Interfactor correlations, we need to test an alternative model (i.e., single-factor).

3. We conclude that, for this particular sample of English students, the single-factor model was the best representation. However, we recommend that:

"Although we found the single-factor-CFA to be the best representation of the BPNSQ for this particular sample of PE students, given the acceptable results found in terms of model fit and factor loadings for the BPNSQ, we recommend that future studies also explore psychometric properties of the 3-factors-CFA".

2.In relation to the use of ESEM in the present manuscript, I can observe that the authors were justified to use ESEM in investigating the BPNSQ structure given very high factor correlations ranging .908 to 1.008 (p. 12, L 306). "As stated by Kline (2016) variables correlating greater than 0.90 cannot be said to measure different constructs" (P13, L 340). However, I believe that the use of ESEM was not justified for the needs satisfaction scale given factor correlations less than .83 where the authors in their response to the reviewers letter characterize as "acceptable" (p 41, L26) (correlations ranging from .67 to .83, p. 14, L366).

Another observation in relation to the use of ESEM is that while ESEM systematically results in few item loadings greater than 1.00, why this is not the case when the model is tested under standard CFA? Shouldn't results be consistent and systematic if an item was really problematic (standard CFA may also provide standardized item loading greater than 1.00, at least in the EQS software)?

After carefully reading the comments made by the two reviewers and editor, we finally decide to delete the ESEM approach to the paper. Honestly, given the superiority of ESEM compared to the CFA showed by previous studies, we think that the comparison of CFA and ESEM approaches was a point of interest in the study.

However, after two revisions, it seems like we were not able to argue correctly the inclusion of the ESEM approach in the current paper. Probably, a solution could have been the inclusion of ESEM 
only for the BPNSQ, but, in our opinion, the reader would find it strange to find the inclusion of ESEM approach for the BPNSQ and not for the BPN-PE.

Therefore, although we would have preferred to keep the ESEM models FOR BOTH SCALES, given the suggestions of Reviewer 1 and Editor, we decided to delete the ESEM approach to the paper.

3.Another important observation is that the authors did not follow reviewers' request for running tests of measurement invariance between the original language data for each instrument and the English language data. Such a test is very important to secure in a technical way the equivalence of item meaning in translation. The authors have stated that they do not have access to the Greek sample (p42, L 14). I am not sure I can understand. Have they asked the data from the corresponding author?

First that all, we agree that the cross-cultural invariance is a good way to evaluate the items equivalence of a scale in different languages. Answering the last question, we have not asked to the authors for the data base with Greek sample. But, the reason why we did not include the crosscultural validation is due to the length of the manuscript. The current version of the paper has more than 7,000 words. If we would have included the cross-cultural validation, it would be necessary to do it for both scales, and this would have meant an important increase in the number of words, tables ... Furthermore, the Editor also agree that is "too deep into the process to push this issue farther". We wanted to keep the focus of the paper clear.

Having said this, given that the BPN-PE has been used in other languages, we totally open the possibility to do a new paper in order to develop a cross-cultural validation of this scale.

4.Further, the authors have not conformed to the request of computing composite reliability and average variance extracted values for the subscales of the instruments.

Following the reviewer suggestion, we have added scores of internal reliability. Specifically, we included scores of Cronbach's alpha, average variance extracted (AVE), and composite reliability.

\section{Further issues for thought}

P2, L 39. Paragraph on purpose of the study appears out of the blue. No preparation of the reader has been made up to this point for the purpose of the study.

We added this sentence as another reviewer asked for us to include a general purpose of the study before we explained the theory and previous research.

We think that it is interesting to introduce the readers to a general purpose of the study.

However, if reviewer still thinks we should delete this sentence, we would not have problem to do it. 
P5, L 125. The sentence should be "The BPN-PE has been developed to examine psychological need satisfaction with Greek-speaking participants...and translated versions have been used to examine the constructs in Spanish language populations..."

We have reworded following the reviewer suggestion. Thanks.

P6, L 145. Hypothesis \#1 should be "A single factor model would not conform to the data while a 3-factor model would conform to the data". The purpose of comparing alternative models is to reject some which have particular implications for the measurement of the constructs. This is different from saying that the 3-factor will be better than a single-factor model. What happens if the three factor model is a little bit better as in the present case?

As we deleted the ESEM approach, and the paper orientation was change to a more applied paper, we have changed the orientation of the first hypothesis.

At the current version, our hypothesis is that the 3-factors-CFA version would display an acceptable psychometric properties (following the original versions):

"We hypothesized that: (1) the BPNSQ and BPN-PE would display a good factorial validity (i.e., acceptable fit indices, factor loadings) and discriminant validity (i.e., reasonable interfactor correlations) through a 3-factor model".

P7, L 166. In Measures section, the authors have not reported fit indices, factor correlations and item loadings based on other studies of the instrument tested. This info should be added so the reader knows how the scale works up to now in other samples and more adequately judge the overall picture of the manuscript.

We agree with the reviewer that it is interesting to include information about the psychometric properties found in previous studies. However, we think that the introduction section (when we talk about previous validations of both scales) could be a better place to include it. In fact, in the previous version we already had information about the BPNSQ: "In these previous studies, the BPNSQ showed an acceptable factorial validity (model fit and factor loading patterns), nomological validity (positive associations with psychological need satisfaction), reliability, and invariance across gender (Sánchez-Oliva et al., 2013, 2014)".

Furthermore, we have included information about the BPN-PE: "In these studies, the BPN-PE reported acceptable values of factorial validity (model fit and factor loading patterns) reliability, and nomological validity (positive associations with perceived autonomy support and subjective vitality)".

Nevertheless, if reviewer would still like us to include this information in the measure section, we would not have problem to do it.

P8, $L$ 183. The BPN-PE was developed in Greek...

Changed. 
P16, L 409. The authors have computed correlations to test for nomological validity using both the single factor representation and the three-factor representation of the BPNSQ. This is not acceptable. Those factors should be used that are based on the model representation finally accepted.

Following the reviewer suggestion, we have deleted the 3-factors CFA model to the nomological validity. As a consequence, given that Table 5 would only have 3 values, we decided to delete this table, and explaining this result by text.

P9, L 226-231. The authors have computed additional analyses of invariance including variancecovariances, and factor latent means (often labelled "structural invariance" analyses). These specific analyses were not originally requested given that theoretical hypotheses should be forwarded and tested in relation to them. Without theoretical hypotheses to be tested, these analyses are meaningless. They differ in nature from the "measurement invariance" analyses requested.

Following the reviewer suggestion, we have deleted the information related to the variancecovariances, and factor latent means invariances.

Also I have not seen in the Discussion section practical implications for measurement based on the invariance analysis performed (by gender).

We included the following sentence:

"This result demonstrates the measurement equivalence of both genders, that is, the measurement structure of the scale (i.e., factor loadings, intercepts, and uniquenesses) does not change for males or females, and it has practical implications, as both questionnaires can be administered regardless of the students' gender".

P16, L 421-424. This future direction is irrelevant to the essence of the present manuscript.

Following the reviewer suggestion, we have deleted this information.

P17, L 433-434. I believe this future direction does not fit to the present manuscript.

In this case, we do not agree with the suggestion of the reviewer, also thinking in the removal of the ESEM approach. Given the superiority of the ESEM and bifactor models when comparing to the CFA solutions (Appleton, Ntoumanis, Quested, Viladrich, \& Duda, 2016; Morin, Arens, \& Marsh, 2016; Myers, Martin, Ntoumanis, Celimli, \& Bartholomew, 2014; Pulido et al., 2017; Stenling, Ivarsson, Hassmén, \& Lindwall, 2015), in our opinion, it is an interesting line for future research. 
Reviewer: 2

\section{Comments to the Author}

I thank the authors for the considerable efforts they have gone to in their revising of this manuscript. I applaud their efforts and believe that this version of the manuscript is far superior to previous versions! I do however, have a few concerns that the authors should address.

Thank you so much for this positive feedback.

1. I think the manuscript is substantially clearer; however, I don't see a compelling argument for why a one-factor solution is tested. Theoretically, why might there be one factor even though the three needs are theoretically distinct? Empirically, why might researchers combine the subscales to create one "general need satisfaction" variable? Please strengthen this justification and provide some references to show that people are in fact using this approach so it warrants investigation.

We now present the one-factor model as a follow-up analysis based on the high factor correlations (larger than 1.0). This is a data-drive analysis to further explore the structure of the data, we do not propose that this is an adequate representation of the theory, but rather a measurement issue that is important to highlight and needs attention in future research.

2. There is no information presented in the data analysis about how invariance models were compared and evaluated.

We have included information about comparison of nested models: "According to Cheung and Rensvold (2002), in the comparison of nested models, a decrease lower than 0.01 on the CFI and TLI, or 0.015 on the RMSEA, are considered to provide an equivalent level of fit to the data".

3. I might be missing something, but I'm not really sure how the "Variance-Covariance" model was tested on a one-factor solution when the one factor solution had no factor covariances?

Following suggestions of another reviewer, we have deleted the information related to the variancecovariances, and factor latent means invariances.

4. I realize that it is implied that the ESEM model has three-factors, but to help readers who aren't as familiar, it might be useful to refer to it as 3-factor ESEM rather than just "ESEM".

After reading comments from R1 and Editor, we decided to delete the ESEM approach to the paper. Please, see our answer to the R1.

5. There are some title issues with the Tables (i.e., bifactor models weren't tested) and labelling issues (e.g., Table 2 has the support items along the top in the wrong order). Is the chi-square in Table 4 the MLR chi-square? Consider presenting the factor loadings from the ESEM models that were not significant as well.

We have changed the tables following the reviewer suggestion. Sorry for the mistake. 
6. Please make the concluding statement in the abstract clearer and directly related to your findings. In other words, right now it reads that both instruments measure "psychological need support" but does not indicate which one measures as one overall factor vs. three separate factors.

We agree with the reviewer that we should include in the abstract which solution was selected in each scale. However, we think it would be better to include in the results statement. We have included as follow:

"For the psychological need-support scale (BPNSQ) the hypothesized 3-factor solution displayed high interfactor correlations ( $r s>1$ ), and a follow-up analysis indicated that the items were represented by a single need-support factor. For the psychological need-satisfaction scale (BPN-PE), we found support for the hypothesized 3-factor solution".

7. On page 2, line 23 a Canadian reference is used to support a world-based generalization. Please specify this sentence is for Canadian children only or add other references to support this statement across many countries.

We totally agree with the reviewer, thank you for the suggestion.

We have changed the reference to a global study:

“Hallal, P. C., Andersen, L. B., Bull, F. C., Guthold, R., Haskell, W., Ekelund, U., ... Wells, J. C. (2012). Global physical activity levels: Surveillance progress, pitfalls, and prospects. The Lancet, 380, 247$257 "$.

8. Page 2, line 35, Consider adding “(e.g., perceptions of psychological needs") after "includes the socio-contextual determinants" to give a reader a clue what "socio-contextual determinants" might be.

Included. Thanks.

9. I appreciate the new concise purpose statement on page 2 - it's much clearer.

Thank you so much for this positive comment.

10. Page 3 line 51-53 is imprecise and somewhat meaningless to the reader. Not all social environments are conducive to PNS.

We have reworded as follow:

"SDT theorists propose that the social environment is a key element for supporting the three basic psychological needs and is effective in facilitating a high-quality motivation and wellness".

11. Page 3, line 58, please inert an "s" on the word "one" in "one action"

We were not sure about the suggestion of the reviewer, but we reworded as follow:

"having a sense of control and volition over ones actions, such as having choice over completing a certain task". 
12. Page 5, line 106, consider rephrasing "were not used" to "were not evaluated" Changed.

13. Page 5, line 120 please consider rewording to "the satisfaction of the three psychological needs in PE"

Reworded as suggested.

14. Page 5, line 124 please consider removing "which we continue in the present study" and rewording to "which we will investigate in the present study"

Reworded as suggested.

15. Page 8, line 186, please insert the Vlachopoulos reference to show readers it was their findings not yours

Included

16. Page 8, line 201 consider adding "was used" after "MLR estimator"

This sentence was reworded as follow:

"Confirmatory Factor Analysis (CFA) was used in conjunction with the robust maximum likelihood (MLR) estimator".

17. Page 9, line 223, I like how the brackets show how invariance constraints were added on the ESEM cross-loadings. Can the same format be used on line 224 (i.e., use the brackets again)?

As we deleted the ESEM approach, this information was deleted.

18. Page 10, I think it' $d$ be useful to mention the correlation that is greater than 1 directly in the section where you discuss the results of the 3-factor CFA rather than only in the section where you discuss the ESEM (just in case someone is cherry picking results and doesn't care to read the ESEM section, they'll see there was this problem with the CFA model).

As we deleted the ESEM approach, this information about the interfactor correlation for the 3factor-CFA was include after the explanation of the model fit and factor loadings.

19. Page 10, line $\mathbf{2 5 0 - 2 5 3}$ is awkward. Please consider rewording.

We reworded as follow:

"There are no established cut-offs for determining unidimensionality or multidimensionality based on factor correlations. However, researchers have argued that correlations of .80 or higher suggest a substantial overlap between factors and in those cases a simpler model may be preferred based on parsimony (John \& Bennet-Martínez, 2000; Kline, 2016)”.

20. Page 13, line 346, what kind of refinement is needed? Removing items? Rewording items? 
We reworded this sentence as follow:

"refinement of this scale (e.g., rewording of items) may be neccesary to be able to distinguish between the three sub-dimensions".

21. Page 15, line 401, please consider inserting what it means from a practical perspective when gender invariance is found. In other words, tell readers why they should be excited and what it means for them.

We included the following sentence:

"Our results demonstrate that the underlying measurement structure of the scale (i.e., factor loadings, intercepts, and uniquenesses) is similar for males or females, which allows for meaningful mean comparisons between males and females. This also has practical implications as both questionnaires can be administered regardless of the students' gender. However, we encourage future research to replicate these findings in younger and older students". 
Comments to the Author:

This is the second revision of this manuscript. To offer just a brief summary, the main goal was the test the factorial validity of the English translations of (1) the Basic Psychological Needs Support Questionnaire (BPNSQ; Sánchez-Oliva et al., 2013) and (2) the Basic Psychological Needs in Physical Education Scale (BPN-PE: Vlachopoulos, Katartzi, \& Kontou, 2011) on a sample ( $=453$ ) of English-speaking adolescent students (12-17 years). Throughout the review process, the peer reviewers and I have been in full agreement that having validated questionnaires to measure need support and need satisfaction in the PE environment in English would be extremely valuable. There was also consensus that the sample used in this study was adequate and the analyses were appropriately and competently conducted. The problems we identified related to the orientation and structure of the manuscript. The first two versions of the manuscript were unfocused, convoluted, overloaded, and hard to read. There were two 12-item instruments. For each, there were 7 competing structural equation models, each evaluated with 8 indices of fit, to test 5 hypotheses. The reviewers and I pleaded with the authors to rethink and clarify the purpose of their work, and to reorganize and streamline their manuscript accordingly. Our motivation, and the reason for our persistence, was that we were hoping to deliver a readable and useful paper to a readership that we anticipated would be fairly large, given the current popularity of SelfDetermination Theory within exercise psychology.

I am happy to report that, although the two peer reviewers have expressed somewhat varying degrees of enthusiasm, both agree that the current iteration of the manuscript represents a big step in the right direction. The convergence of visions has clearly begun and I must applaud the authors for their willingness to take the suggestions of reviewers under serious consideration, for undertaking a very demanding overhaul of their manuscript, and for delivering a manuscript that is now much more readable, lucidly written, and genuinely useful to researchers. I must admit to being skeptical initially as to whether we would ever get to this point, given how different the two visions of the manuscript were at baseline. So, I am honestly thankful that we have made this much progress.

While it is important to recognize the great progress, we are not quite at the finish line yet. Both reviewers are still expressing certain reservations and I do not wish to minimize their importance.

1. Not surprisingly, the concerns center mainly around the BPNSQ and the apparent promotion in the manuscript of a single-factor model. Both reviewers raise this issue. Reviewer \#1 writes: "The authors have concluded that a single factor model is the best representation of the structure of the BPNSQ scores (p. 17, L 440; p. 1, L 7). This is problematic given that a single factor model representation of scale scores is against the theory where three factors are proposed to exist. Such a finding seriously limits the value of the present manuscript in the extant literature." Similarly, Reviewer \#2 writes: "I don't see a compelling argument for why a one-factor solution is tested. Theoretically, why might there be one factor even though the three needs are theoretically distinct? Empirically, why might researchers combine the subscales to create one 'general need satisfaction' variable?" If I may attempt an interpretation of what the reviewers are saying, perhaps this is something that can be resolved with a relatively painless rewrite. I hope the 
authors can agree that it would be hard to fully justify an a priori focus on single-factor models. In the current version of the manuscript, the notion of single-factor models appears for the first time at the very end of the introduction (hypotheses). Readers have not been given any theoretical reasons to anticipate the testing of single-factor models. This certainly seems puzzling given the basis of the questionnaires on the SDT. Now, that said, the question of a single-factor model certainly arises naturally when we get to the Results and see that the factors of the BPNSQ are

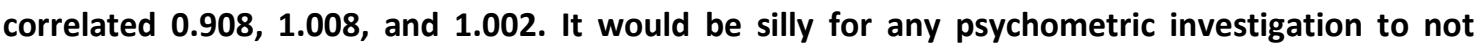
highlight the complete lack of discriminant validity of the questionnaire given these numbers. I am not $100 \%$ sure but I think that the reviewers would find it acceptable if, besides the statements to this effect in the Discussion (e.g., "these findings suggest that specific factors of the BPNSQ did not distinguish"), you also followed-up the results from the 3-factor model with results from an ad hoc single-factor model, to further drive home the important message that researchers should not expect to get any more information out of the BPNSQ, whether they scored it as three factors or one. Also implied in this suggestion is that you really do not have a good (i.e., theoretical or psychometric) reason to report results on a single-factor model for the BPN-PE, given factor intercorrelations of $0.707,0.831$, and 0.677 .

We would like to thank the Editor for this compressive feedback and the recommendation to asses this important comment. Please, see below our answer to this comment:

"We agree with the reviewer that the single-factor solution of the BPNSQ is against the hypothesis and theory, as well as against previous studies who also used this scale (Sánchez-Oliva, Leal, et al., 2014; Sánchez-Oliva et al., 2013). However, in the scientific area the results do not always show what you expect to find, and in our opinion, this aspect is important in science.

In the current study, it is clear that we expected to find an acceptable psychometric property for the 3-factors-CFA model. This acceptable scores were confirmed with respect to the model fit and factor loadings. However, we found interfactor correlations higher that we expected. Taking into account the results that we found, as the editor said: "It would be silly for any psychometric investigation to not highlight the complete lack of discriminant validity of the questionnaire given these numbers". Given these results, we cannot accept to propose the 3-factor-CFA model as the best solution, and we had to test another alternative model (i.e., single-factor solution).

In this regard, as we explain during the discussion, the lack of discriminant validity (i.e., interfactor correlations) has been a relatively common issue in previous studies where a perceived need support scale was tested. Furthermore, several previous studies used the need-support measure as a single factor (Ntoumanis, 2005; Rutten et al., 2012; Sánchez-Oliva, Sánchez-Miguel, et al., 2014; Standage et al., 2005; Zhang et al., 2011).

Therefore, given the results that we found, we only can:

1. To test the 3-factor-CFA model.

2. Given de Interfactor correlations, we need to test an alternative model (i.e., single-factor).

3. We conclude that, for this particular sample of English students, the single-factor model was the best representation. However, we recommend that: 
"Although we found the single-factor-CFA to be the best representation of the BPNSQ for this particular sample of PE students, given the acceptable results found in terms of model fit and factor loadings for the BPNSQ, we recommend that future studies also explore psychometric properties of the 3-factors-CFA".

2. Reviewer \#1 is still expressing questions about the true scientific necessity of the ESEM models, noting that the insistence on ESEM in the context of this manuscript may indicate some sort of "preoccupation" with "emphasizing the statistics rather than the essence of the paper for the applied researcher." To help you place this statement in proper context, please note that it comes from a respected colleague who lives and breathes statistics. I must admit that I agree. I have been in this business for 25 years, since the 1980s. I have lived through those times when a paper would get published by simple having "factor analysis" in the title, then "confirmatory factor analysis," then "general linear modeling," then "growth curve modeling," then "multilevel regression," and so forth. What the peer reviewer is calling a "preoccupation" with statistics is essentially the thinly veiled scientism that remains so painfully prevalent in exercise psychology. As a field, we may not have made any progress in advancing our agenda (to my knowledge, there are presently no globally observable practices that are based on exercise psychology research) but we have always been at the cutting edge of multivariate statistics. Having received a recent rejection from this same journal after being scolded by a reviewer for such serious infractions as daring to report Cronbach's alpha (evidently, an embarrassingly outdated statistic for the avantgarde field of exercise psychology), I believe I do understand the "quantoid" psyche and the profound psychological need to include the statistical method "du jour." This is why I was so pleased to see that the authors dropped the bifactor and hierarchical CFAs; I imagine that this decision was probably made with great trepidation and took some courage. Is ESEM contributing much meaningful information or clarity in the context of the present paper to justify the space devoted to it? Not really. Does it add or change the interpretation of the results in some profound way? Not really. Will its inclusion probably confuse, rather than help, some readers? Probably. However, we have now asked the authors twice to reconsider the true scientific necessity of comparing modeling options in the context of this particular manuscript, which was supposed to be testing the English translation of two questionnaires, and the ESEM-CFA comparison is still here ("ESEM models allowing for near zero cross-loadings of indicators onto non-target factors would show a better fit to the data"). At this point, I am willing to concede that this must be of great importance to the authors for reasons that are not readily apparent to the rest of us and I am ready to move on. If possible, I only ask the authors to consider this point made by Reviewer \#1: even if the use of ESEM is needed for BPNSQ, is it really necessary for BPN-PE given the fact that its factor intercorrelations do not indicate a problem?

After carefully reading the comments made by the two reviewers and editor, we finally decide to delete the ESEM approach to the paper. Honestly, given the superiority of ESEM compared to the CFA showed by previous studies, we think that the comparison of CFA and ESEM approaches was a point of interest in the study.

However, after two revisions, it seems like we were not able to argue correctly the inclusion of the ESEM approach in the current paper. Probably, a solution could have been the inclusion of ESEM only for the BPNSQ, but, in our opinion, the reader could find strange to find the inclusion of ESEM approach for the BPNSQ and not for the BPN-PE. 
Therefore, although we would have preferred to keep the ESEM models FOR BOTH SCALES, given the suggestions of Reviewer 1 and Editor, we decided to delete the ESEM approach to the paper.

3. Reviewer \#1 raises the issue that, while invariance by gender is good to have, invariance across cultures is arguably a much more crucial consideration in the context of a cross-cultural adaptation of questionnaires. The Reviewer notes that the previous reply "we don't have access to the Greek sample" is somewhat ambiguous; it seems to imply that the authors do have access to the Spanish data but not the Greek data; however, it does not clearly explain whether an effort was made to obtain a copy of the Greek data. At this point, I feel we are too deep into the process to push this issue farther. We already have a full-length manuscript and we are in the third round of review. I would be happy to see the statement in the Limitations section ("future research should perform cross-cultural validation to analyze whether these scales work equally well in different countries") be reworded and strengthened, along the lines that a test of cross-cultural invariance should be among the top priorities for future research. In my mind, this issue, in terms of importance, should be placed after the need to investigate the lack of discriminant validity of the BPNSQ but before the need to test for temporal invariance (and certainly before the need to test hierarchical and bifactor models).

Please, see our answer to this comment:

"First that all, we agree that the cross-cultural invariance is a good way to evaluate the items equivalence of a scale in different languages. Answering the last question, we have not asked to the authors for the data base with Greek sample. But, the reason why we did not include the crosscultural validation is because size reasons. The current version of the paper has more than 7,500 words. If we would have included the cross-cultural validation, it would be necessary to do it for both scales, and this would have meant an important increase in the number of words, tables ... Furthermore, the Editor also agree that is "too deep into the process to push this issue farther".

Having said this, given that the BPN-PE has been used in other languages, we totally open the possibility to do a new paper in order to develop a cross-cultural validation of this scale".

Specific minor suggestions

1. Throughout the manuscript, sometimes you use the expression "psychological needs satisfaction" (or "support") and sometimes the expression "psychological need satisfaction" (or "support"). Please change all expressions to "psychological need satisfaction" (not "needs").

Changed following the reviewer suggestion, but we keep "needs" when we refer to the specific scales (i.e., Basic Psychological Needs Support Questionnaire (BPNSQ) and Basic Psychological Needs in Physical Education Scale (BPN-PE)).

2. Throughout the manuscript, please search for ampersand (\&) used in citations outside of parentheses. These should be changed to "and" (please, see APA manual, 6th edition, section entitled "One work by multiple authors," p. 175: "Precede the final name in a multiple-author citation in running text by the word 'and'. In parenthetical material, in tables and captions, and in the reference list join the names by an ampersand (\&)").

Changed. Thanks. 
3. P2, L20: "The World Health Organization (WHO, 2010) state..." should be "states"

Changed.

4. P2, L42-43: "perceived students' satisfaction of the autonomy, competence, and relatedness psychological needs." Please reword as "perceived satisfaction of the psychological need of students for autonomy, competence, and relatedness."

Changed. Thanks for the suggestion.

5. P5, L113: "an English version of the BPNSQ have not yet been evaluated" should be "has" Changed.

6. P12, L296: "in several different languages" should be "in several languages" (please see APA manual, 6th edition, section on "Redundancy," p. 67).

Changed.

7. P16, L425: "the data was ..." The Latin "data" is the plural form of "datum." Therefore, this should be "the data were..." Please, see APA manual, 6th edition, section entitled "Agreement of Subject and Verb," p. 79.

Changed.

8. Please correct the titles of Tables 1 and 2 (still contain references to models now removed)

Changed. Sorry for the mistake.

References

Appleton, P. R., Ntoumanis, N., Quested, E., Viladrich, C., \& Duda, J. L. (2016). Initial validation of the coach-created Empowering and Disempowering Motivational Climate Questionnaire (EDMCQC). Psychology of Sport and Exercise, 22, 53-65. http://doi.org/10.1016/j.psychsport.2015.05.008

Morin, A. J. S., Arens, A. K., \& Marsh, H. W. (2016). A Bifactor Exploratory Structural Equation Modeling framework for the identification of distinct sources of construct-relevant psychometric multidimensionality. Structural Equation Modeling: A Multidisciplinary Journal, 23, 116-139. http://doi.org/10.1080/10705511.2014.961800

Myers, N. D., Martin, J. J., Ntoumanis, N., Celimli, S., \& Bartholomew, K. J. (2014). Exploratory bifactor analysis in sport, exercise, and performance psychology: A substantive-methodological synergy. Sport, Exercise, and Performance Psychology, 3, 258-272. http://doi.org/10.1037/spy0000015

Ntoumanis, N. (2005). A prospective study of participation in optional school physical education using a self-determination theory framework. Journal of Educational Psychology, 97, 444-453. http://doi.org/10.1037/0022-0663.97.3.444 
Pulido, J. J., Sánchez-oliva, D., Leo, F. M., Sánchez-cano, J., García-calvo, T., Pulido, J. J., ... Garcíacalvo, T. (2017). Development and validation of Coaches 'Interpersonal Style Questionnaire Development and validation of Coaches 'Interpersonal Style Questionnaire. Measurement in Physical Education and Exercise Science, 0(0), 1-13. http://doi.org/10.1080/1091367X.2017.1369982

Rutten, C., Boen, F., \& Seghers, J. (2012). How school social and physical environments relate to autonomous motivation in physical education: The mediating role of need satisfaction. Journal of Teaching in Physical Education, 31, 216-230.

Sánchez-Oliva, D., Leal, J., Marreiros, J., Pulido, J. J., \& García-Calvo, T. (2014). Validação do Questionário de Apoio às Necessidades Psicológicas Básicas em Portugal [Validation of the Basic Psychological Needs Questionnaire in Portugal]. Psicologia Reflexão E Crítica, 27(4), 615624. http://doi.org/10.1590/1678-7153.201427402

Sánchez-Oliva, D., Leo, F. M., Amado, D., Cuevas, R., \& García-Calvo, T. (2013). Desarrollo y validación del cuestionario de apoyo a las necesidades psicológicas básicas en educación física [Development and validation of the questionnarie of basic psychological need support in physical education]. Motricidad. European Journal of Human Movement, 30, 53-71.

Sánchez-Oliva, D., Sánchez-Miguel, P. A., Kinnafick, F.-E., Leo, F. M., \& García-Calvo, T. (2014). Physical education lessons and physical activity intentions within Spanish Secondary Schools: A Self-Determination perspective. Journal of Teaching in Physical Education, 33, 232-249.

Standage, M., Duda, J. L., \& Ntoumanis, N. (2005). A test of Self-Determination Theory in school physical education. The British Journal of Educational Psychology, 75, 411-433. http://doi.org/10.1348/000709904X22359

Stenling, A., Ivarsson, A., Hassmén, P., \& Lindwall, M. (2015). Using bifactor exploratory structural equation modeling to examine global and specific factors in measures of sports coaches' interpersonal styles. Frontiers in Psychology, 6(1303). http://doi.org/10.3389/fpsyg.2015.01303

Zhang, T., Solmon, M. A., Kosma, M., Carson, R. L., \& Gu, X. (2011). Need support, need satisfaction, intrinsic motivation, and physical activity participation among middle school students selfdetermination theory. Journal of Teaching in Physical Education, 30, 51-68. 